\title{
Complex reservoir sedimentation revealed by an unusual combination of sediment records, Kangaroo Creek Reservoir, South Australia
}

\author{
John Tibby · Peter Gell • Gary Hancock • \\ Malcolm Clark
}

\begin{abstract}
Despite their direct links to human use, reservoirs are not widely utilised, relative to natural lakes, for deriving sediment histories. One explanation is the complex sedimentation patterns observed in water storages. Here a highly unusual combination of sedimentary records is used to determine the sedimentation history of Kangaroo Creek Reservoir, South Australia. We compare contiguous high resolution $(0.5 \mathrm{~cm}$ sampling interval) diatom records from an almost $1.3 \mathrm{~m}$ core extracted from the bottom of the reservoir and from a $0.4 \mathrm{~m}$ monolith of sediment perched $15 \mathrm{~m}$ above the reservoir bottom on a disused bridge that was submerged following initial reservoir
\end{abstract}

J. Tibby $(\bowtie) \cdot$ P. Gell

Geographical and Environmental Studies, University of Adelaide, Adelaide, SA 5005, Australia

e-mail: john.tibby@adelaide.edu.au

P. Gell

School of Science \& Engineering, University of Ballarat, Ballarat, VIC 3353, Australia

G. Hancock

Rivers and Coasts, CSIRO Land and Water, Canberra, ACT 2601, Australia

M. Clark

School of Mathematical Sciences, Monash University, Clayton, VIC 3800, Australia filling in 1970. The diatom histories are supplemented by evidence provided by other indicators, most notably radionuclide concentrations and ratios. Interestingly, despite the fact that the reservoir has been $>20 \mathrm{~m}$ deep for more than $70 \%$ of its recorded history, distinct sections of the reservoir bottom core, but not the bridge monolith, are dominated by nonplanktonic diatoms. We attribute the occurrences of these phases to inflows that occur following heavy catchment rains at times when the reservoir is drawn down. These characteristic sections have, in turn, been used to refine the site's chronology. Despite having a length of almost $1.3 \mathrm{~m}$, a variety of data suggests that the core has not recovered pre-reservoir sediment, but rather spans the period from 1981 (11 years after first filling) to 2001, when the core was extracted. It is clear, therefore, that sediments in the bottom of the reservoir are accumulating rapidly $\left(>7 \mathrm{~cm}_{\text {year }}{ }^{-1}\right)$, although more than $40 \%$ of this deposition occurs in less than $5 \%$ of the time. It appears that in the period 1996-2001, quiescent sedimentation rates, both in the perched bridge locality and on the reservoir bottom, slowed in response to reduced stream flow. Our findings indicate that, with caution, complex patterns of sedimentation in water storages can be disentangled. However, it was difficult to precisely correlate diatom sequences from the two records even in periods of quiescent sedimentation, suggesting that reservoir bottom diatom sequences should be interpreted with considerable caution. Furthermore, while storm-derived inflows such as those identified may 
deliver a substantial proportion of sediment and phosphorus load to storages, the ensuing deposition patterns may render much of the phosphorus unavailable to the overlying waters.

Keywords Reservoir - Diatoms - Sequence slotting $\cdot$ Correlation $\cdot$ Sedimentation rates

\section{Introduction}

Although by no means as well studied as natural lakes, reservoirs are increasingly being utilised as sites for sediment-based research (Clark and Wasson 1986; Hall et al. 1999), with varied objectives including reconstruction of water quality (Hall et al. 1999; Yoshikawa et al. 2000), atmospheric and catchment pollution (Kim 2005; Shotbolt et al. 2006) and sediment tracing (Wasson et al. 1987; Garzanti et al. 2006). Reservoirs have important features as palaeolimnological sites. In particular, sediment regularly accumulates rapidly due to high trap efficiency and positioning on high order streams (Clark and Wasson 1986), while often extensive historical information, particularly related to hydrology, helps to identify processes affecting site and catchment histories.

A major reason for a relative lack of reservoirbased sediment studies is the potential for them to exhibit complex sediment deposition patterns as a result of factors such as the drawdown of water levels and the large and variable discharges of input streams (Shotbolt et al. 2005). Here we investigate two sediment records from Kangaroo Creek Reservoir. One record represents a typical sediment sequence, a core extracted from a deep-water site using percussion coring. The second record is more unusual: a monolith sampled in situ from sediments deposited on a disused bridge perched approximately $15 \mathrm{~m}$ above the reservoir bottom which has been submerged for almost all the time since the Reservoir was first filled in 1970. Through independent analysis and comparison of the two records, we show that they exhibit distinctly different deposition histories, allowing us to elucidate information about the pattern and timing of sedimentation. In turn, the implications for reservoir palaeolimnological studies are highlighted.

\section{Descriptions of sites studied}

Kangaroo Creek Reservoir $\left(34^{\circ} 52^{\prime} \mathrm{S}, 138^{\circ} 46^{\prime} \mathrm{E}\right)$ is a relatively large (current capacity approximately $19 \times 10^{7} \mathrm{~m}^{3}$, dam wall height $63 \mathrm{~m}$ ) domestic water storage on the River Torrens, South Australia (Fig. 1). It is the fifth largest capacity storage in South Australia. Kangaroo Creek Reservoir drains a

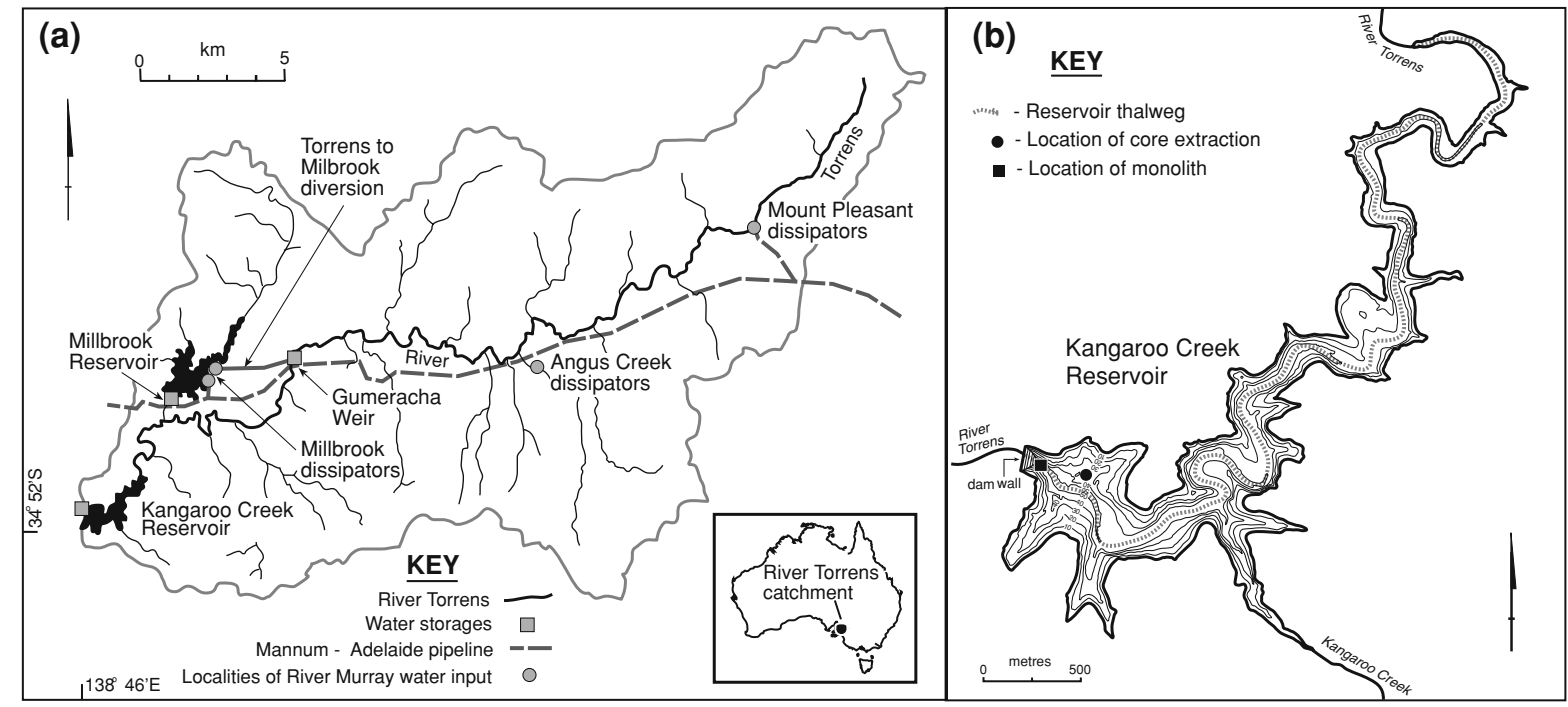

Fig. 1 a Location of Kangaroo Creek Reservoir and the Upper River Torrens catchment. Also shown in a are the major localities for water transfer in the Upper Torrens system. b Bathymetry of Kangaroo Creek Reservoir and locations for extraction of the core and bridge monolith sediment records 
catchment of approximately $290 \mathrm{~km}^{2}$ that is characterised by a variety of mixed land uses, of which broadscale grazing ( $>60 \%$ area) and native vegetation are the dominant types (Anon 2000). Natural inflows to reservoirs in the Torrens system are augmented by inter-basin transfers of water from the River Murray (approximately $80 \mathrm{~km}$ to the east). Inflows of River Murray water into the system are limited by the capacity of the pipeline $\left(300,000 \mathrm{~m}^{3}\right.$ a day) to deliver water. By contrast, owing to the absence of upstream storages, with the exception of Millbrook Reservoir (capacity $16,500 \times 10^{6} \mathrm{~m}^{3}$ ) which drains approximately $12 \%$ of the catchment (Heneker 2003), natural rainfall events can generate substantial inflow into the reservoir, although some of this discharge can be diverted to Millbrook Reservoir via pipeline from the pool at Gumeracha Weir (Fig. 1).

\section{Materials and methods}

During lowering of Kangaroo Creek Reservoir's water level for valve maintenance, a monolith $40 \mathrm{~cm}$ long, $25 \mathrm{~cm}$ wide and approximately $10 \mathrm{~cm}$ thick was extracted using a flat-bladed shovel from the surface of the former Gorge Road Bridge. The bridge is approximately $15 \mathrm{~m}$ above the current base of the reservoir. The monolith was supported by a board, wrapped and transported to the laboratory. A sediment core was extracted from approximately $5 \mathrm{~m}$ of water using a percussion corer (Chambers and Cameron 2001). Coring was halted before basal sediments were reached for fear that the corer would become fixed in the clay-rich sediments. In the laboratory, diatom samples were removed from previously unexposed surfaces at $0.5 \mathrm{~cm}$ resolution from the monolith and the core. Contiguous centimetre-thick samples were taken from the monolith for radionuclide determinations. The smaller volume of the core meant that contiguous 5-cm-thick slices were required for radionuclide determination using gamma spectroscopy. Organic matter was estimated by firing oven dried samples at $550^{\circ} \mathrm{C}$ for $2 \mathrm{~h}$ on contiguous centimetre samples from both records (Dean 1974).

Uranium and thorium series radionuclides and fallout ${ }^{137} \mathrm{Cs}$ were determined by gamma spectrometry (Murray et al. 1987). A known weight (30-80 g) of dry homogenized sediment was mixed with a polyester resin and formed into a known geometry.
The radioactivity of the sample was measured using high-purity $\mathrm{Ge}$ detectors. The nuclides measured include ${ }^{238} \mathrm{U},{ }^{226} \mathrm{Ra},{ }^{210} \mathrm{~Pb},{ }^{228} \mathrm{Ra},{ }^{228} \mathrm{Th}$, and ${ }^{137} \mathrm{Cs}$.

Charcoal particles $>125 \mu \mathrm{m}$ were counted from the monolith to aid in the refinement of the chronology as particles of this size often reflect local fires as they are transported relatively short distances by air (Clark and Hussey 1996). Using a technique based on Rhodes (1995), weighed samples were dispersed in $\sim 50^{\circ} \mathrm{C} 10 \% \mathrm{KOH}$ for $12 \mathrm{~h}$, centrifuged and the supernatant discarded. Non-charcoal organic matter was bleached in $4 \% \mathrm{H}_{2} \mathrm{O}_{2}$ for $12 \mathrm{~h}$. Samples were then passed through a $125-\mu \mathrm{m}$ sieve and the contents retained. All black, angular, particles were counted at $50 \times$ magnification in a graduated petri dish using a Zeiss Sterni 2000-C binocular microscope. Charcoal was not analysed from the core.

Diatoms were prepared using a modified version of Battarbee et al. (2001), with 2-3 h treatments in $10 \%$ $\mathrm{HCl}$ and $10 \% \mathrm{H}_{2} \mathrm{O}_{2}$, respectively, to remove carbonate and organic matter. Following each of these steps, samples were washed three times in distilled water and allowed to settle for $12 \mathrm{~h}$. Prepared slurries were dried on coverslips which were then inverted and mounted on permanent slides using Naphrax ${ }^{\circledR}$ mounting medium. Diatoms were identified at $1000 \times$ magnification, using either a Nikon Eclipse E600 with differential interference contrast optics or with an Olympus BH2 microscope with brightfield illumination. Diatoms were identified with reference to a variety of sources, in particular, Krammer and Lange-Bertalot (1986, 1988, 1991a, b) and Sonneman et al. (2000). There was some disparity between analysts regarding the identity of Staurosira construens Ehrenb. and Staurosira elliptica (Ehrenb.) D. M. Williams et Round. Hence, these taxa were grouped for data analysis and display.

In order to identify key points of change in the perched bridge diatom monolith, we undertook stratigraphically constrained cluster analysis using CONISS (Grimm 1987) using Euclidean distance. By contrast, hierarchical cluster analysis of the core record was used to identify diatom assemblages which had similar composition, regardless of their stratigraphic position. We undertook this analysis in SPSS for Windows 13.0 (SPSS 2004) with squared Euclidean distance as the distance measure. The resultant dendrogram (Appendix 1, available online as Electronic Supplementary Material) is not presented here due to both the large sample size $(n=255)$ and the 
fact that the stratigraphically unconstrained cluster could not be readily displayed in relation to the diatom stratigraphy. Rather, membership of four clusters is displayed on the diatom stratigraphy (Fig. 5). In both cases, cluster analysis was undertaken on all taxa with a relative abundance $\geq 1 \%$.

We used sequence slotting (Thompson and Clark 1989) of the two diatom records to identify likely correlations between the core and the bridge monolith diatom deposits. In order to ensure maximum comparability between the records, we only undertook slotting on the four most abundant planktonic diatom taxa with relative abundances expressed as a proportion of the total of these taxa. Core samples dominated by non-planktonic diatoms (shaded in Fig. 5) were first removed from the analysis. Since the procedure in Clark (1985) is limited to a maximum of 100 samples, it was necessary to first average every two samples (representing a centimetre of sediment) from the core. This created a data set of 68 core samples and 70 monolith samples. For every pair of samples, the dissimilarity in their diatom assemblages was measured using a chord distance based on the relative proportions of the four diatom taxa. The two sequences were then combined, subject to the stratigraphic constraints, into a single, combined sequence with minimum total dissimilarity (equivalently, minimum combined path length) using a dynamic programming approach (Delcoigne and Hansen 1975). Correlations between the monolith and core were deduced from the relative positions of the corresponding sample in the combined sequence.

We utilised changes in radioisotopes to correlate between the perched bridge monolith record and the reservoir bottom core sequence. In particular we used the activity ratio of the two fallout nuclides ${ }^{210} \mathrm{~Pb}_{\mathrm{ex}}$ and ${ }^{137} \mathrm{Cs}$. Since both these nulcides are adsorbed to the surfaces of sediment grains, their ratio is less subject to nuclide concentration variations associated with particle size differences. Given the different settings of the core and the monolith, such differences are likely.

Historical stream discharge data and water levels were obtained from the Department of Land, Water and Biodiversity Conservation, South Australia. Unfortunately, water level data were only available from June 1979, while stream discharge data extended to the beginning of 1974. Water levels were converted to reservoir volumes using ratings curves supplied by SA Water.

\section{Results}

${ }^{210} \mathrm{~Pb}$ stratigraphy and monolith chronology

Only the bridge monolith chronology is addressed in this section. The chronology of the bottom core is more problematic and is discussed in detail in the Discussion section. ${ }^{210} \mathrm{~Pb}_{\mathrm{ex}}$ values in the monolith decline irregularly with depth (Fig. 2a), with several non-monotonic features including peaks in concentration at 1-2, 20-21 and 38-39 $\mathrm{cm}$. The sections between $12-18$ and $29-32 \mathrm{~cm}$ are characterised by, respectively, elevated and constant values relative to samples above. ${ }^{210} \mathrm{~Pb}_{\mathrm{ex}}$ in the core also generally declines with depth in a non-monotonic fashion (Fig. 2b), with values relatively constant between 35 and $60 \mathrm{~cm}$ and from $110 \mathrm{~cm}$ to the base of the core $(128.5 \mathrm{~cm}) .{ }^{210} \mathrm{~Pb}_{\mathrm{ex}}$ values are somewhat variable in the upper $30 \mathrm{~cm}$ of the core, while there is a peak between 60 and $75 \mathrm{~cm}$.

The chronology of the monolith is assessed using the two commonly used approaches to ${ }^{210} \mathrm{~Pb}$ geochronology, the CIC (constant initial ${ }^{210} \mathrm{~Pb}_{\mathrm{ex}}$ concentration) and the CRS (constant rate of ${ }^{210} \mathrm{~Pb}_{\mathrm{ex}}$ supply) algorithms (Robbins 1978; Appleby and Oldfield 1978). The CIC algorithm assumes the ${ }^{210} \mathrm{~Pb}_{\mathrm{ex}}$ activity of sediment being deposited is constant, and the sediment age at depth $x$ is determined from

$t_{i}=-\frac{1}{\lambda} \ln \left[\frac{C(0)}{C(x)}\right]$

where $t(x)$ is the age at depth $x, C(0)$ is the initial ${ }^{210} \mathrm{~Pb}_{\mathrm{ex}}$ concentration of sediment being deposited and $C(x)$ is the ${ }^{210} \mathrm{~Pb}_{\mathrm{ex}}$ activity at depth $x$. Obtaining a chronology for the monolith profile using Eq. (1) is complicated by the difficulty in defining $C(0)$. To obtain a meaningful chronology using CIC the value of $C(0)$ needs to have been approximately constant over the chronological period of interest. If this occurs there will be a monotonic decrease in ${ }^{210} \mathrm{~Pb}_{\mathrm{ex}}$ with depth. Examination of the depth profile shows that constant $C(0)$ is unlikely to have occurred. At the monolith surface the ${ }^{210} \mathrm{~Pb}_{\mathrm{ex}}$ concentration is about $60 \mathrm{~Bq} \mathrm{~kg}^{-1}$. The concentration $C(x)$ increases immediately below the surface to a value of $\sim 100 \mathrm{~Bq} \mathrm{~kg}^{-1}$, before decreasing again. More nonmonotonic behaviour is seen at various depths in the monolith, especially in the $17-22 \mathrm{~cm}$ depth interval. 
Fig. 2 Radionuclide data from Kangaroo Creek Reservoir records. Excess ${ }^{210} \mathrm{~Pb}$ concentrations in $(\mathbf{a})$ Kangaroo Creek Reservoir bridge monolith and (b) core. Ratio of excess ${ }^{210} \mathrm{~Pb}$ to ${ }^{137} \mathrm{Cs}$ in the monolith (c) and core (d). Ratio of ${ }^{226} \mathrm{Ra}$ to ${ }^{228} \mathrm{Ra}$ in the monolith (e) and core (f) The shaded core sections in $\mathbf{b}, \mathbf{d}$ and $\mathbf{f}$ are characterised by diatom assemblages not found in the monolith and are discussed below. $Y$-axes are scaled to highlight the proposed correlations (indicated by arrows) between the data series (a)
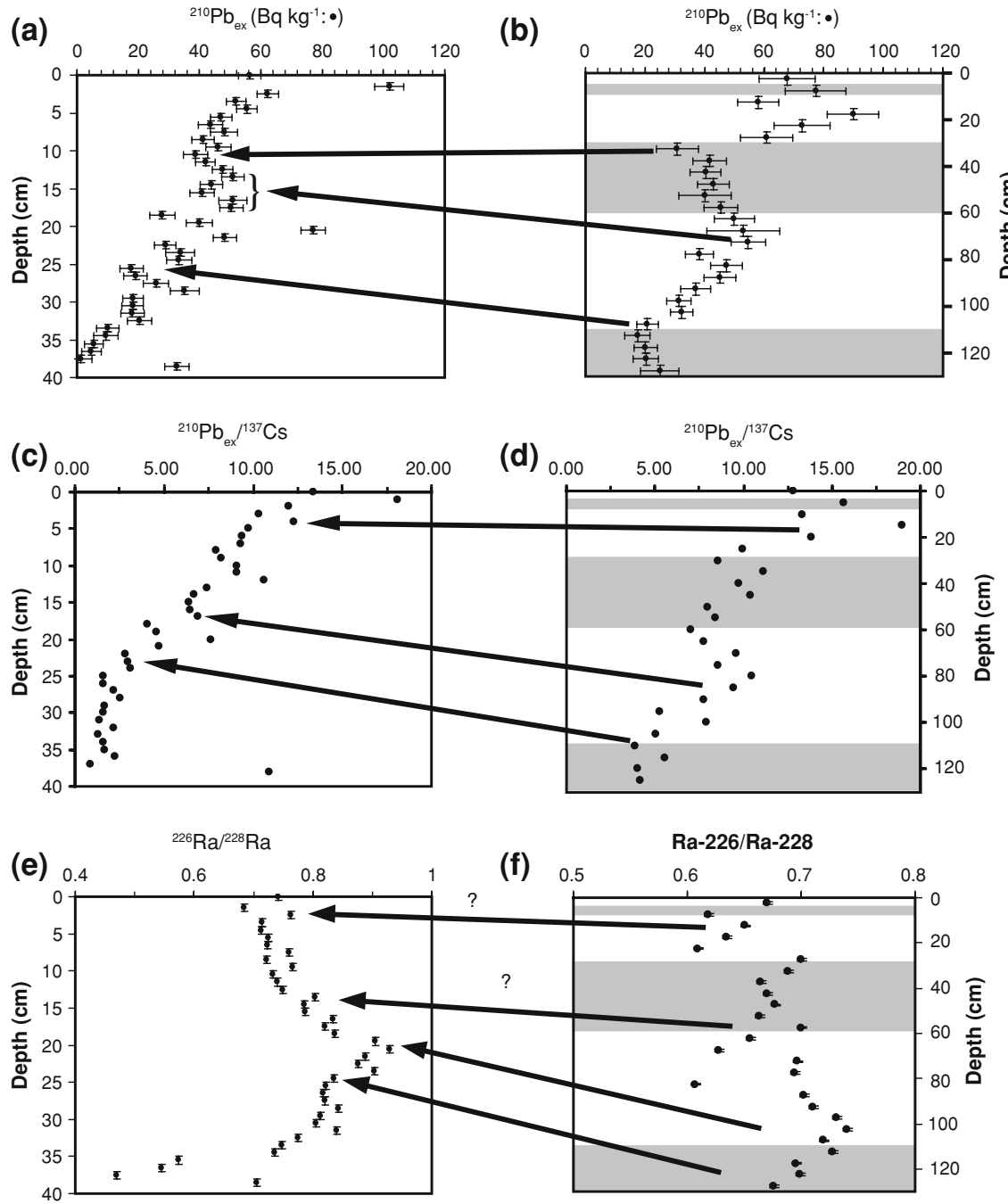

The ages calculated using Eq. 1 are shown in Fig. 3 (open circles). The age trend reflects the nonmonotonic ${ }^{210} \mathrm{~Pb}_{\mathrm{ex}}$ concentrations, with large scatter and inverted ages at some points where ages actually increase with depth.

The CRS algorithm assumes constant ${ }^{210} \mathrm{~Pb}_{\mathrm{ex}}$ flux, therefore allowing variable ${ }^{210} \mathrm{~Pb}_{\mathrm{ex}}$ activity of the depositing sediment. The sediment age is determined from

$t_{i}=-\frac{1}{\lambda} \ln \left[\frac{A(i)}{A(\infty)}\right]$

where $A(x)$ is the integrated activity $\left(\mathrm{Bq} \mathrm{m}^{-2}\right)$ of excess ${ }^{210} \mathrm{~Pb}$ below depth $x$, and $A(\infty)$ is the total integrated activity of the sediment column, given by
$A(\infty)=\sum_{i=1}^{\infty} c_{i} m_{i}$

where $c_{i}$ and $m_{i}$ is the concentration and mass of the $i$ th depth interval. Because the complete ${ }^{210} \mathrm{~Pb}_{\mathrm{ex}}$ profile was not captured by the monolith $\left({ }^{210} \mathrm{~Pb}_{\mathrm{ex}}\right.$ is detected in the basal layer) $A(\infty)$ cannot be measured absolutely, and Eq. 2 cannot be applied. Consequently we have used a variation on the traditional CRS algorithm, as given by Appleby (2001). Here we essentially "calibrate" the rate of ${ }^{210} \mathrm{~Pb}$ supply using horizons of known age, rather than estimating it from $A(\infty)$. For the monolith the horizons of known age correspond to the sediment surface (the year 2001 at $x=0 \mathrm{~cm})$ and the age of initial filling of the reservoir (1970 at $x=36 \mathrm{~cm})$. A depth of $36 \mathrm{~cm}$ is 
Fig. 3 a Kangaroo Creek Reservoir bridge monolith age-depth relationships based on 2a. derived from constant initial concentration $(C I C)$ and constant rate of supply $(C R S)$. Also shown are the concentrations of macrocharcoal particles in the monolith and the two chronological tie-points used to constrain the CRS-derived age-depth relationship. b Bridge monolith sedimentation rates

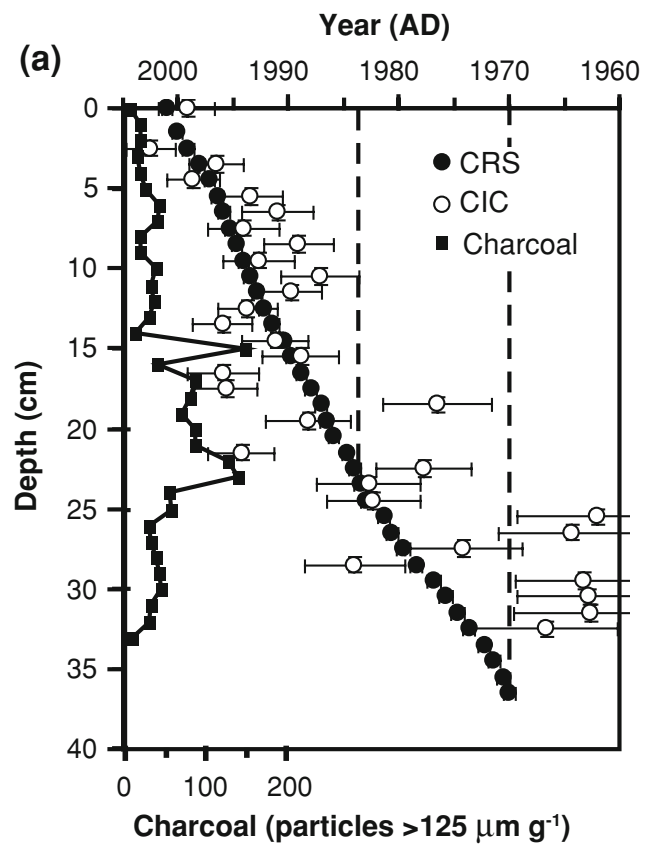

(b)

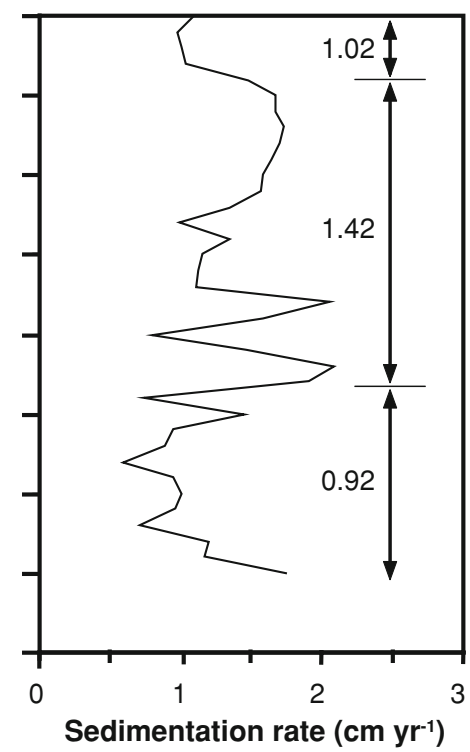

chosen to represent sediment delivered in 1970 rather than the absolute base of the monolith $(x=38.5 \mathrm{~cm})$ due to the likelihood that the anomalous $2.5 \mathrm{~cm}$ layer of sediment at the base of the monolith sediment constitutes material of unknown origin deposited during or shortly after construction of the dam ceased, and should not therefore be considered part of the modelled profile. A third horizon of known age is revealed by a major charcoal peak seen in the 23$24 \mathrm{~cm}$ depth section (Fig. 3); this peak was correlated with the largest wild fire in the reservoir's history which occurred in February 1983. We hypothesise that elevated charcoal levels above this point are related to continued in-wash of 1983 charcoal from the catchment. Thus, we model ${ }^{210} \mathrm{~Pb}_{\mathrm{ex}}$ as having two periods of constant flux, from 1970 to 1983 , and from 1983 to 2001. For each period the flux $(F)$ is determined from

$F=\frac{\lambda A\left(t_{1}, t_{2}\right)}{\mathrm{e}^{-\lambda t_{1}}-\mathrm{e}^{-\lambda t_{2}}}$

where $A\left(t_{1}, t_{2}\right)$ is the ${ }^{210} \mathrm{~Pb}_{\mathrm{ex}}$ inventory between the horizons of known ages $t_{1}$ and $t_{2}$ occurring at depths $x_{1}$ and $x_{2}$. The sediment age $(t)$ at depth $x$ is given by

$t=\frac{1}{\lambda} \ln \left(\mathrm{e}^{-\lambda t_{1}}+\frac{\lambda}{F} A\left(x, x_{1}\right)\right)$

where $A\left(x, x_{1}\right)$ is the ${ }^{210} \mathrm{~Pb}_{\mathrm{ex}}$ inventory between depth $x$ and $x_{2}$. The ${ }^{210} \mathrm{~Pb}_{\text {ex }}$ fluxes, $F$, are $379 \mathrm{~Bq} \mathrm{~m}^{-2}$ year $^{-1}$ for 1971-1983 and $561 \mathrm{~Bq} \mathrm{~m}^{-2}$ year $^{-1}$ for 19832001. Both these values are many times greater than the flux expected from direct atmospheric fallout for Adelaide ( $\sim 50 \mathrm{~Bq} \mathrm{~m}^{-2}$ year $^{-1}$, Turekian et al. 1977), indicating that ${ }^{210} \mathrm{~Pb}_{\mathrm{ex}}$ delivery to the reservoir is mainly associated with ${ }^{210} \mathrm{~Pb}_{\mathrm{ex}}$ bound to sediment eroded from the catchment hillslopes. This result is not surprising given the high trap efficiency of reservoirs for sediment. While a catchment source of ${ }^{210} \mathrm{~Pb}_{\mathrm{ex}}$ tends to argue against CRS as the appropriate algorithm for ${ }^{210} \mathrm{~Pb}_{\mathrm{ex}}$ geochronology (Appleby and Oldfield 1992), the repeated filling of the reservoir in most winters (see below), would have provided relatively constant sediment source, and hence ${ }^{210} \mathrm{~Pb}_{\mathrm{ex}}$ input to the reservoir. We contend, therefore, that the CRS approach is a reasonable approximation for determining the ${ }^{210} \mathrm{~Pb}_{\mathrm{ex}}$ chronology.

The piecewise CRS chronology determined using Eq. 5 (Fig. 3, closed circles) shows the same general trend as the CIC ages, but with much tighter constraints on the dated horizons shown in Fig. 3 as vertical dashed lines. Given the scatter in the CIC ages, and the fact that the CRS chronology is well calibrated at the base and mid-depth horizons, we consider the CRS chronology to be more credible and it is adopted hereafter.

A profile of sediment accumulation determined from the piecewise CRS chronology of the monolith 
is shown in Fig. 3b. The profile indicates higher rates of accumulation in the 1980s and 1990s. Mean rates for the periods 1971-1983, 1983-1997 and 19972001 are given and show that sediment accumulation was about $50 \%$ lower before 1983 compared to 1983-1997 (0.92 $\pm 0.16 \mathrm{~cm} \mathrm{year}^{-1}$ compared to $\left.1.42 \pm 0.05 \mathrm{~cm} \mathrm{year}^{-1}\right)$. There is evidence for lower sedimentation in the monolith after 1997 $\left(1.03 \pm 0.09 \mathrm{~cm} \mathrm{year}^{-1}\right)$.

As noted above, an independent ${ }^{210} \mathrm{~Pb}$-based chronology for the core was not derived as the variable nature of the ${ }^{210} \mathrm{~Pb}_{\mathrm{ex}}$ profile does not lend itself to CIC modelling, while a CRS-based chronology could not be applied because the complete postreservoir sediment profile was not recovered. Thus, unlike the monolith, the basal age of the core is not known and the rate of ${ }^{210} \mathrm{~Pb}_{\mathrm{ex}}$ supply could not be determined absolutely. As a result, we explore the chronological relationships between the monolith and the core in the following Discussion section based on correlations between the two records, in addition to their relationship to historical events.
Diatom stratigraphies

The majority of the diatom record from the Kangaroo Creek monolith is dominated by planktonic diatoms. The major exception to this observation is in zone 4 where, for approximately the bottom half of the zone, the total proportion of plankton is less than $50 \%$ (Fig. 4). Of the non-planktonic taxa represented in zone four, Achnanthidium minutissimum (Kütz.) Czarn. is the most abundant. Fragilaria capucina Desm. is also an important part of the assemblages in this zone. Key features of the remaining planktondominated zones include peaks in Asterionella formosa Hass. and Aulacoseira granulata (Ehr.) Simonsen across the zone 4/3 boundary, a peak in Cyclotella stelligera Cleve \& Grun. in Cleve) Van Heurck in the bottom half of zone 3 and a peak in Aulacoseira subborealis (Nygaard) Denys, Muylaert and Krammer in zone 2.

Unlike the monolith, the core shows distinct phases dominated by non-planktonic diatoms (shown shaded in Fig. 5). The assemblages in these phases are, for the

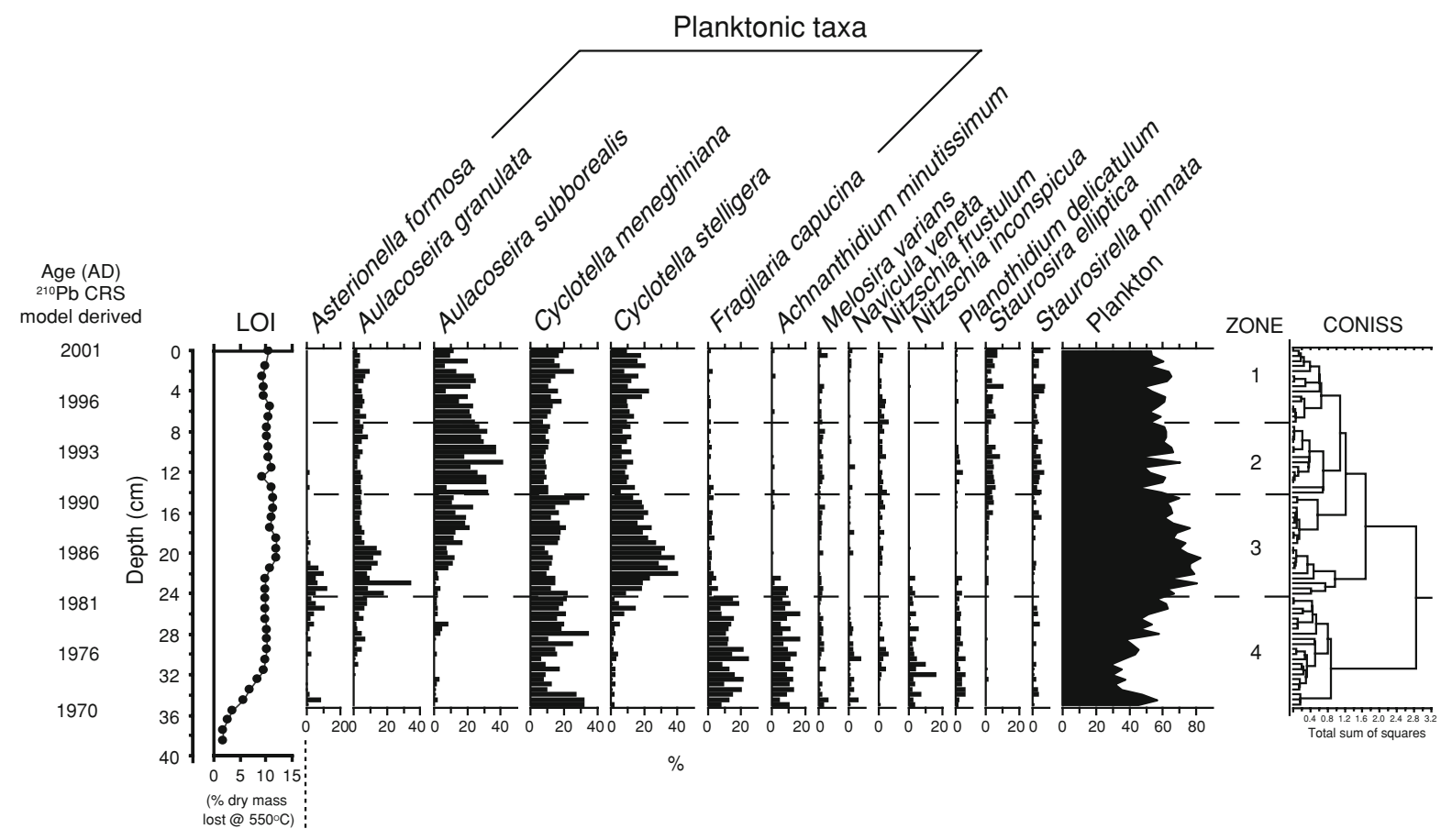

Fig. 4 Summary diatom diagram from Kangaroo Creek Reservoir monolith. Also shown is the loss-on-ignition (LOI) after firing at $550^{\circ} \mathrm{C}$. Note that diatoms were not sampled below the $35-35.5 \mathrm{~cm}$ sample 
most part, identified by cluster analysis as distinct from other assemblages in the core (group 1 in Fig. 5). These sections are dominated by Staurosirella pinnata (Ehr.) Williams \& Round, S. construens and S. elliptica and, additionally, in the upper part of the record, by Melosira varians Agardh. The depths of sections are 5.5-9.5, 14-16.5, 30.5-62.5, 79.5, $107.5-128.5 \mathrm{~cm}$, the latter being the basal sample (Fig. 5). Notably, losson-ignition (LOI) values indicate that these parts of the core are characterised by organic matter that is less variable than in adjacent core sections (standard deviation in LOI in these sections: $1.2 \%$, in remaining sections: $2.2 \%$ ) (Fig. 5). The remaining core sections, defined as groups 3 and 4, have much higher proportions of planktonic diatoms. The predominant planktonic diatoms that characterise these sections are A. subborealis, A. granulata, C. stelligera and $C$. meneghiniana Kütz. The latter taxon is notably more abundant above $30 \mathrm{~cm}$, while $A$. subborealis is particularly abundant between $62.5-75 \mathrm{~cm}$.

\section{Discussion}

Conventional ${ }^{210} \mathrm{~Pb}$ dating approaches were not able to provide a chronology for the core. Hence, we firstly utilise the history of inflow events to propose ages for the deposition of bulk sediment units in the core and then assess these ages using correlations between indicators in the core and the ${ }^{210} \mathrm{~Pb}$ dated bridge monolith.

Timing, mechanisms and character of bulk sediment deposition in the Kangaroo Creek Reservoir core

In contrast to surface sediments in other south-east Australian reservoirs, where planktonic diatoms are $>50 \%$ in all sites $>5 \mathrm{~m}$ maximum depth (Fig. 2 in Tibby 2004), sections of the Kangaroo Creek Reservoir core have very low proportions of planktonic diatoms. These sections are also characterised by sediment geochemistry and LOI that has lower variability than other sections. Given that planktonic diatoms dominate deep reservoir sediments generally and, specifically, regularly dominate water column phytoplankton in Kangaroo Creek Reservoir (unpublished SA Water data), it is unlikely that units dominated by non-planktonic diatoms were deposited when the reservoir was deep. However, despite the fact that non-planktonic-dominated sections make up over $45 \%$ of the core profile, there have been no

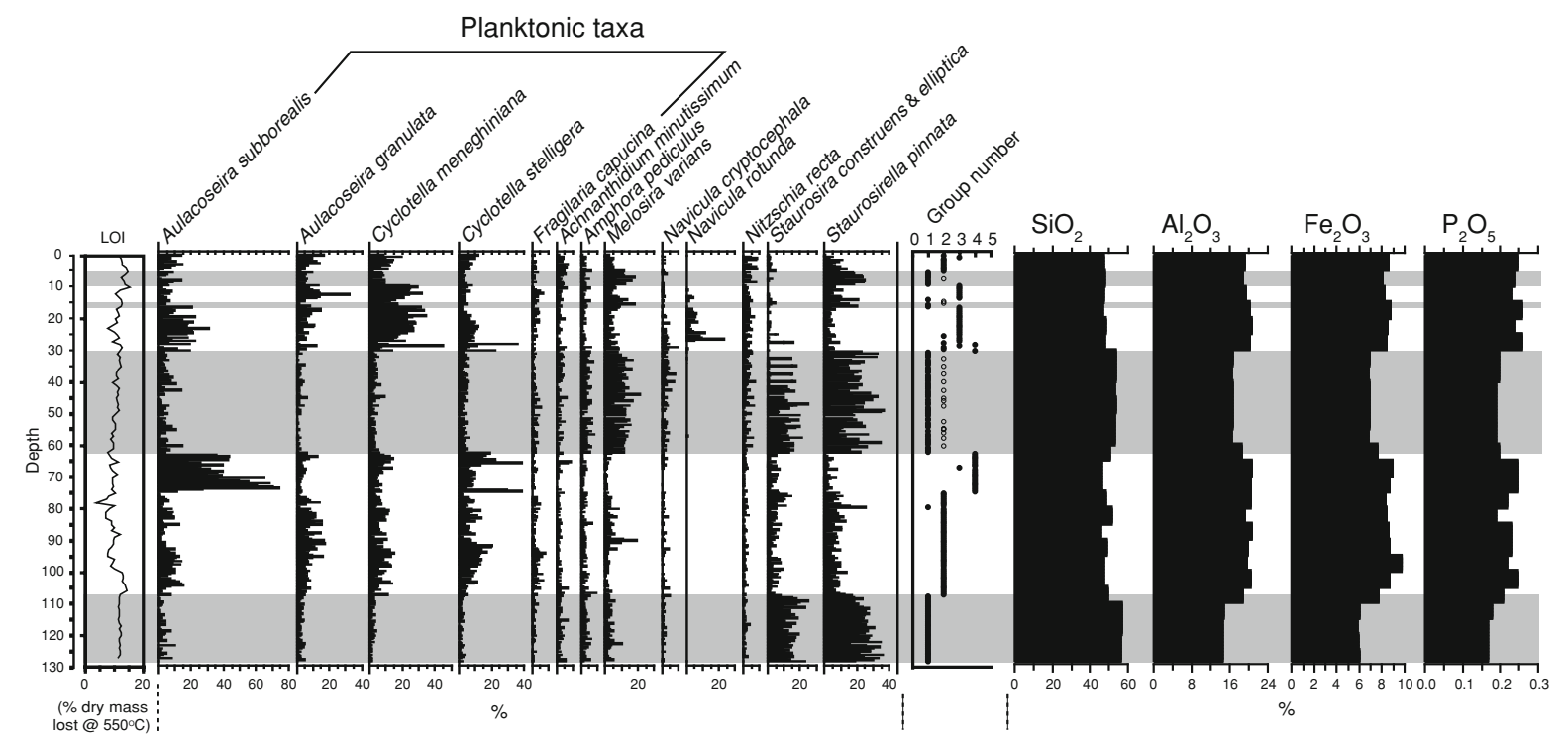

Fig. 5 Summary diatom and major element diagram from Kangaroo Creek Reservoir core. Also displayed is the group to which each sample belongs as determined by cluster analysis. Note that the shaded samples dominated by non-planktonic diatoms are either in group one or are individual two samples (shown by hollow circles) located in regions dominated by group one assemblages. LOI data are plotted at the mid-point of 5-cm slices. Note that the major elements are scaled to their maximum abundance 
prolonged periods of low reservoir water levels. Water levels lower than $15 \mathrm{~m}$ occurred less than $15 \%$ of the period mid-1979 to mid-2001 (Fig. 6) and the longest period of water levels $<15 \mathrm{~m}$ was less than 6 months (25.3.94-13.9.94). Hence, prolonged low stands appear an unlikely mechanism to explain the prevalence of non-planktonic-diatom-dominated sediments in Kangaroo Creek Reservoir.

Reservoirs are known to deposit large volumes of sediment via density currents in short-lived events (Outhet 1991; Shotbolt et al. 2005). These currents travel along the reservoir bottom as a result of a relatively high density that originates from factors such as lower temperature or elevated suspended solid concentrations. Sediment proxies deposited by these currents are often characterised by relatively low variability (Tibby 2001; Shotbolt et al. 2005), as is the case for the core LOI, diatom and major element data (Fig. 5). In Burrinjuck Reservoir, NSW, Australia density currents have been documented at thicknesses exceeding $50 \mathrm{~cm}$ (Wasson et al. 1987; Tibby 2001). Such deposition may occur infrequently, e.g. when heavy rainfall occurs while reservoirs are drawn down (Wasson et al. 1987;
Shotbolt et al. 2005). We contend that this mechanism explains the deposition of thick, relatively homogenous sediments in the Kangaroo Creek Reservoir core and their absence in the monolith. Furthermore, these deposits were likely to have been deposited at times when the reservoir filled quickly following substantial draw down. Such circumstances combine high stream power with shorter transport distances from the inflow to the core site. This interpretation permits a refinement of the core's chronology.

In late June 1981, in response to the highest catchment discharges $\left(>25 \times 10^{7} \mathrm{~m}^{3} /\right.$ month $)$ in over 20 years, water levels in Kangaroo Creek Reservoir rose from approximately $26 \mathrm{~m}$ deep to over $35 \mathrm{~m}$ deep, representing an increase in reservoir volume from approximately $5.7 \times 10^{6} \mathrm{~m}^{3}$ to $11 \times 10^{6} \mathrm{~m}^{3}$ (Fig. 6). Given that a number of data sources indicate that the core sediment record commences at around this time, we are confident that the basal core sediment section was deposited at this time. A similar set of environmental conditions also occurred in late August 1992, when the reservoir almost doubled in volume $\left(9.9 \times 10^{6} \mathrm{~m}^{3}-18.7 \times 10^{6} \mathrm{~m}^{3}\right)$ in a single

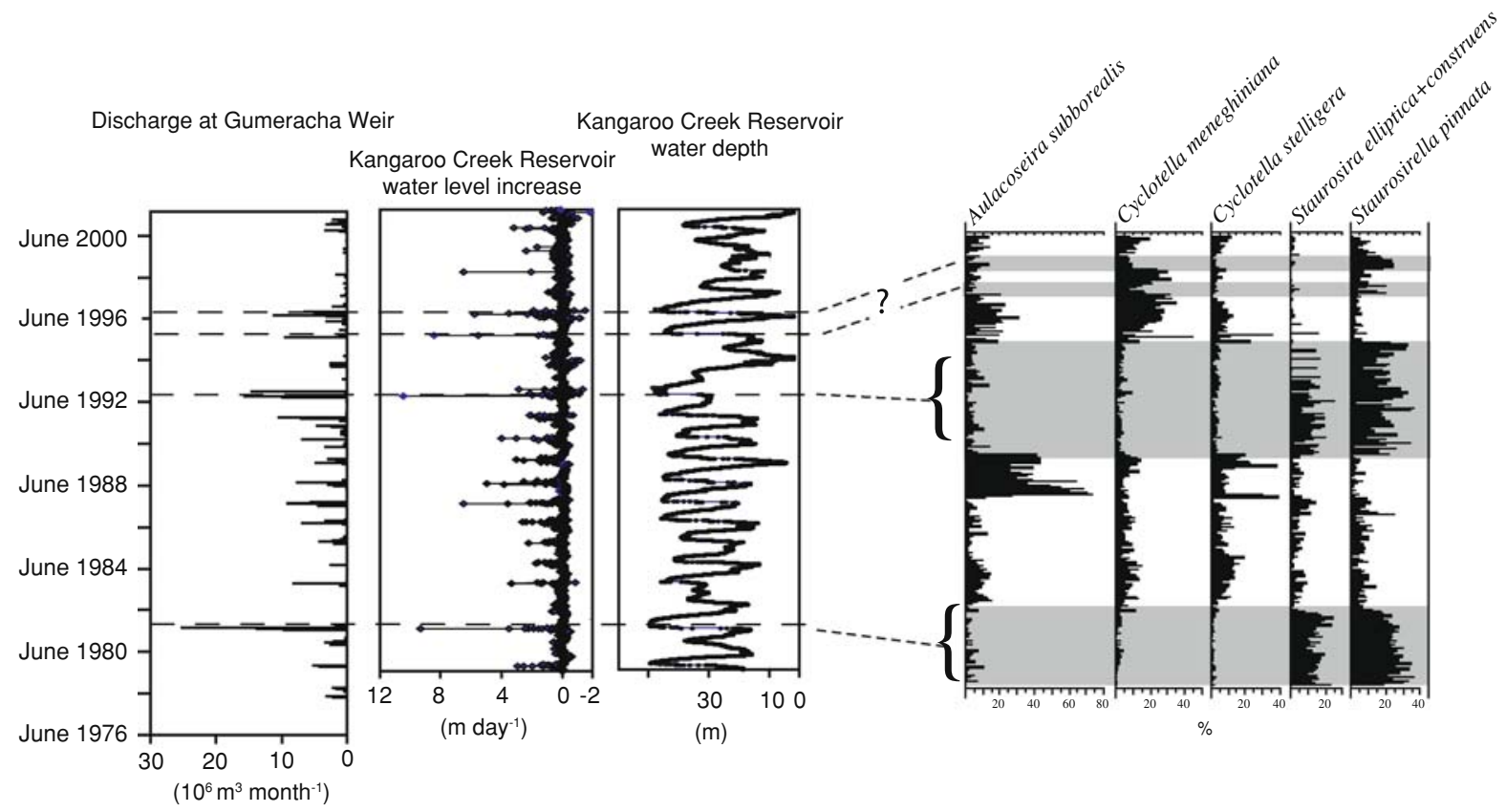

Fig. 6 Monthly discharge over Gumeracha Weir (upstream of Kangaroo Creek Reservoir), water level change in metres/day in Kangaroo Creek Reservoir and summary diatom diagram from the Kangaroo Creek Reservoir core. It is suggested that, at the times of high stream discharge and rapid water level change, core sections dominated by non-planktonic diatoms were deposited 
day (Fig. 6). Hence, it is probable that this event deposited the sediments between 30.5 and $62.5 \mathrm{~cm}$. The final two core sections dominated by nonplanktonic diatoms are considerably smaller, and they cover 2.5 and $3.5 \mathrm{~cm}$ of core. We hypothesise that these sediments were deposited in association with substantial inflows and rapid volume increases of over $4 \times 10^{6} \mathrm{~m}^{3}$ and $3 \times 10^{6} \mathrm{~m}^{3}$, respectively, in July 1995 and July 1996.

Short-lived events such as those documented above may contribute the bulk of sediment and phosphorus load to water storages (Davis and Koop 2006). However, burial of sediment-bound phosphorus in bulk deposits may mean that little is available to the overlying waters, in a situation similar to that described for heavy metals by Callender (2000). Sediment phosphorus concentrations in the two largest density current units are lower than adjacent sediment units (Fig. 5). Hence, it appears unlikely, in the case of Kangaroo Creek Reservoir, that deposition of sediment-bound phosphorus during density inflows had a dramatic effect on the reservoir's nutrient status. This is both because it is likely that much of the deposited phosphorus would have been rapidly buried and because the absolute concentrations of phosphorus in these sediments were lower than those deposited during quiescent sedimentation.

\section{Assessment of density current-derived ages}

Diatom and radionuclide data are used to assess the sediment ages derived in the preceding section. The lack of a robust independent core chronology means that correlations between the $\left({ }^{210} \mathrm{~Pb}\right.$-dated) monolith and the undated core form the basis of this assessment. Diatom records from Kangaroo Creek Reservoir were produced at high resolution using $0.5-\mathrm{cm}$ contiguous increments. Hence, attempted correlations of the bridge monolith and the core focus on these records, with other data used to assess these correlations. Sequence slotting of the multivariate diatom sequences was used to identify possible points of correlation between the records, while visual assessments of the patterns in radionuclide data are used to assess the robustness of these correlations. In all, there were twenty-two locations where the core sequence could be slotted into the perched bridge sediment sequence. Summary results from the slotting exercise are shown in Fig. 7, with the full output in Appendix 2 (available online as Electronic Supplementary Material).

Sequence slotting suggests that approximately the bottom third of the record preserved in the bridge monolith record is not found in the core, with a group of basal core samples "slotted" between the 20 and $20.5 \mathrm{~cm}$ samples in the monolith. This outcome is consistent with visual examination of the diatom data. A. minutissimum and F. capucina, which are abundant below $24 \mathrm{~cm}$ in the monolith record (average 10 and $14 \%$, respectively) (Fig. 4), are considerably less abundant in the core (Fig. 5). Other indicators support this notion that the early (pre-1980s) part of the reservoir's history is not preserved in the core. Fig. 2 $\mathrm{c}-\mathrm{d}$ shows that the basal sediments of the core, which have the lowest ${ }^{210} \mathrm{~Pb}_{\mathrm{ex}} /{ }^{137} \mathrm{Cs}$ ratios of $\sim 4$, only have analogues in the upper $25 \mathrm{~cm}$ of the monolith record. A third line of evidence correlating the basal core age with post-1980 monolith sediment is provided by the ${ }^{226} \mathrm{Ra} /{ }^{228} \mathrm{Ra}$ activity ratio. A significant peak in this ratio exists at $20-25 \mathrm{~cm}$ in the monolith record, a peak which is reflected in the core over the depth 95$115 \mathrm{~cm}$. Hence, taken together, the diatom record and the ratios of ${ }^{210} \mathrm{~Pb}_{\mathrm{ex}} /{ }^{137} \mathrm{Cs}$ and ${ }^{226} \mathrm{Ra} /{ }^{228} \mathrm{Ra}$ suggest that the core sections below $95 \mathrm{~cm}$ are correlated to between 20 and $25 \mathrm{~cm}$ in the bridge monolith record (Fig. 8). Diatom slotting data suggest a younger age for the basal sediments than do the radionuclide data (Fig. 8). Although there are some differences between the indicators, together they suggest that sediments deposited before 1981 were not recovered in the Kangaroo Creek Reservoir core. This finding supports the interpretation that a density current deposited the basal core sediments in June 1981.

The multiple tie points indicated by the diatombased slotting data (Fig. 7), which "slot" 62.5$107.5 \mathrm{~cm}$ core sediments between 6 and $18.5 \mathrm{~cm}$ in the bridge sediment record, are broadly supported by the ${ }^{210} \mathrm{~Pb}_{\text {ex }}$ data (Fig. 8). In particular, a peak in the ${ }^{210} \mathrm{~Pb}_{\mathrm{ex}}$ values centred on the $70-75 \mathrm{~cm}$ core sample appears to correlate to a variable ${ }^{210} \mathrm{~Pb}_{\text {ex }}$ peak in the monolith between 13 and $18 \mathrm{~cm}$ (Fig. 2a, b). The ${ }^{210} \mathrm{~Pb}_{\mathrm{ex}} /{ }^{137} \mathrm{Cs}$ ratio is also supportive of the diatom slotting with ratios in the core sections from 60 to $105 \mathrm{~cm}$ averaging 8.23 (s.d. 1.2) and those of the bridge monolith from 6 to $18 \mathrm{~cm}$ averaging 8.18 (s.d. 1.6). However, at a finer scale, the diatom-based slotting results provide somewhat younger estimates of the points of correlation with core sediments from 


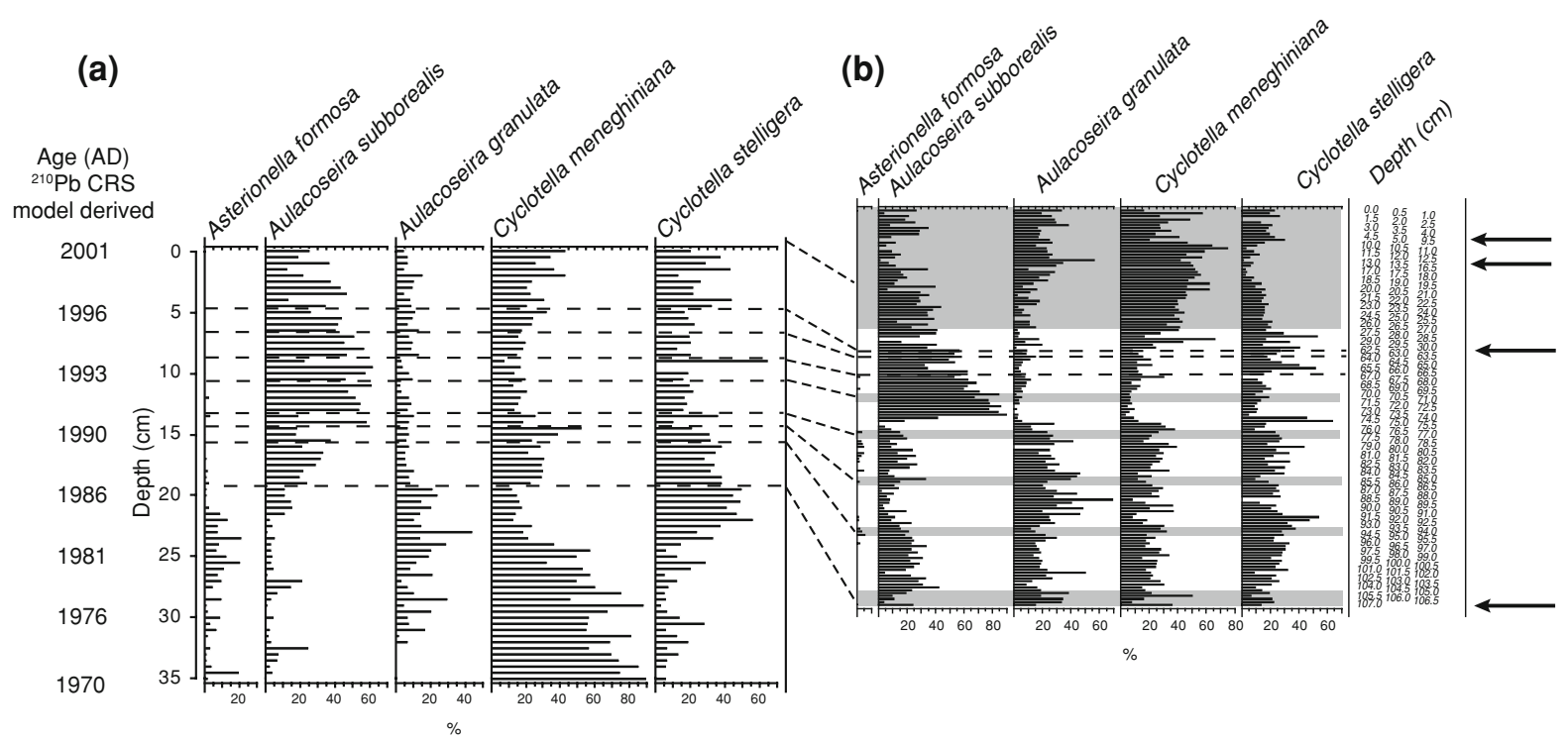

Fig. 7 Attempted correlation between Kangaroo Creek Reservoir monolith (a) and core (b) diatom sequences derived from sequence slotting. Note that where samples are shaded in the core record, a number of samples are "slotted" between monolith samples, where a dashed line is shown only a single sample is slotted. Arrows highlight points at which core sections dominated by non-planktonic diatoms have been removed (see Fig. 5)
Fig. 8 Summary of correlations based on ${ }^{210} \mathrm{~Pb}_{\mathrm{ex}},{ }^{210} \mathrm{~Pb}_{\mathrm{ex}} /{ }^{137} \mathrm{Cs}$ ratio, ${ }^{226} \mathrm{Ra} /{ }^{228} \mathrm{Ra}$, diatom (sequence slotting) data and that derived by ascribing dates to inferred density currents. Note that ambiguous correlations are not displayed

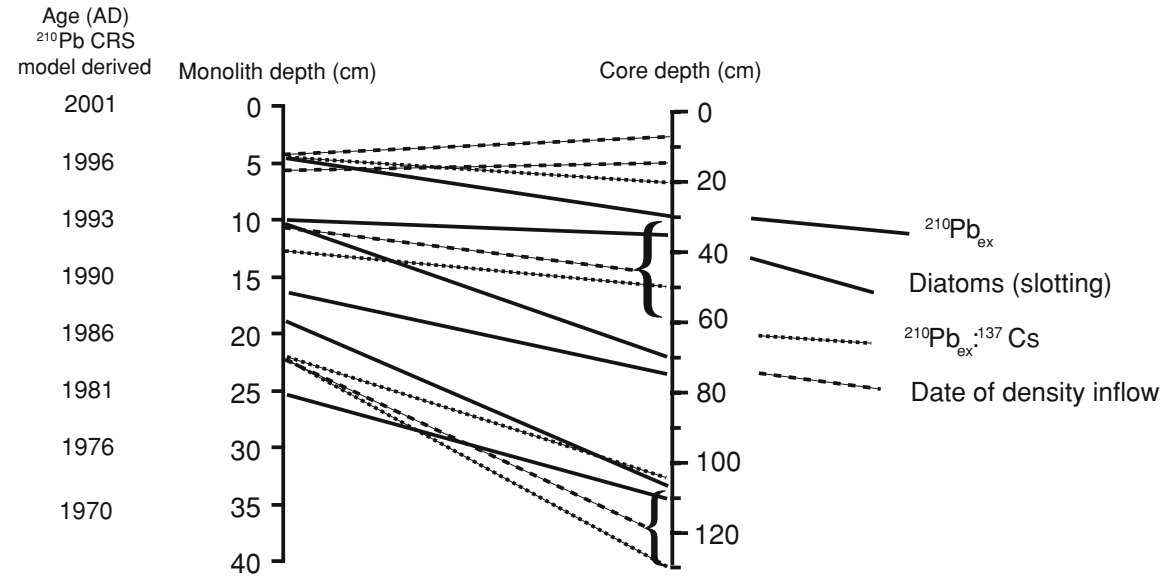

74.5 to $85.5 \mathrm{~cm}$ "slotted" between the 13.5 and $14 \mathrm{~cm}$ samples in the bridge monolith (Figs. 7 and 8). Indeed, age-depth estimates derived from the diatom sequence slotting data suggest that core sediments are consistently more recent than those inferred from density current deposits (Fig. 9).

The core section $30.5-62.5 \mathrm{~cm}$ is dominated by non-planktonic diatoms and was excluded from sequence slotting. We have suggested, based on correlating density current deposits with historical data, that this section of the core was deposited in
1992. Applying the ${ }^{210} \mathrm{~Pb}_{\mathrm{ex}}$-based chronology for the monolith (Fig. 3) would mean that these core samples should correlate to between 11 and $13 \mathrm{~cm}$ (dated to 1992) in the monolith (Fig. 8). The ${ }^{210} \mathrm{~Pb}_{\mathrm{ex}}$ data and the ${ }^{210} \mathrm{~Pb}_{\mathrm{ex}} /{ }^{137} \mathrm{Cs}$ ratio suggest this is the case (Figs. 2, 8). By contrast, the diatom slotting data suggest that diatom core sequences immediately below this unit (i.e. those from 62.5 to $63.5 \mathrm{~cm}$ ) slot above $7 \mathrm{~cm}$ in the monolith (dated to 1995) and therefore provide somewhat later age estimates for the core sediments. Given the size of stream inflows 


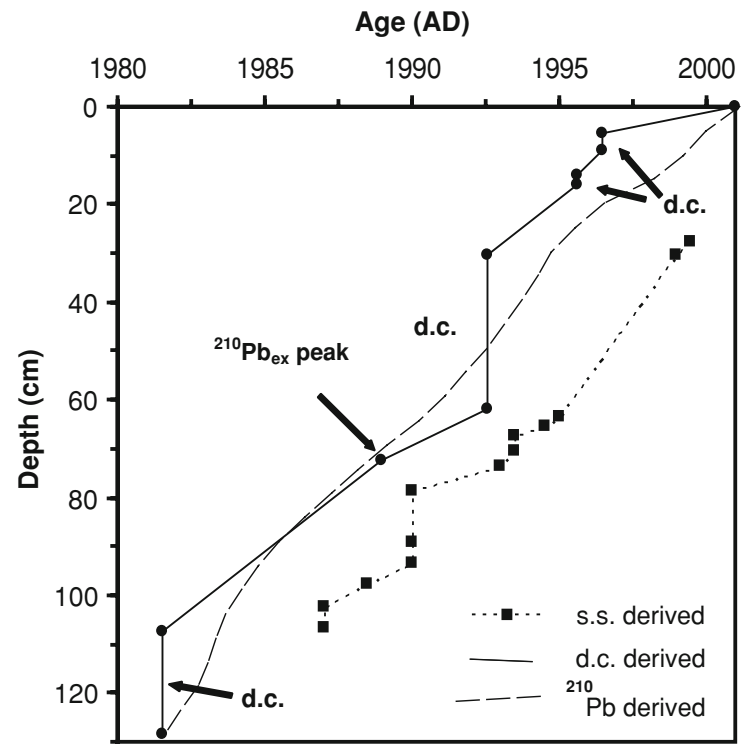

Fig. 9 Age-depth relationship for the Kangaroo Creek core derived from sedimentation events and core-monolith correlations outlined in this study. Density current (d.c). Age-depth relationships derived from sequence slotting (s.s.) of diatom assemblages and CRS modelling of the ${ }^{210} \mathrm{~Pb}_{\mathrm{ex}}$ are also shown. Note that the d.c. derived relationship is the preferred chronology (see text for details)

and water level change in June 1992, we assign this date, rather than the 1995 age suggested by sequence slotting (particularly given the problems with these data highlighted below), to this core section.

An unexpected outcome of the sequence slotting suggests that diatom assemblages from the upper $27.5 \mathrm{~cm}$ of the core are not represented in the monolith. Importantly, this occurs despite the exclusion of thirteen samples dominated by non-planktonic taxa from the analysis, see Appendix 2 (available online as Electronic Supplementary Material). By contrast, correlations between density currents and water level change (Fig. 6) suggest the upper $30 \mathrm{~cm}$ of the core was deposited between late 1992 and mid 2001. During this period, the Gorge Road Bridge was predominantly submerged (Fig. 6) and thus it would be expected that diatoms are preserved in both records. The ${ }^{210} \mathrm{~Pb}_{\mathrm{ex}}$ chronology suggests that this period is preserved in the upper $12 \mathrm{~cm}$ of the monolith. ${ }^{210} \mathrm{~Pb}_{\mathrm{ex}} /{ }^{137} \mathrm{Cs}$ ratios in the upper $30 \mathrm{~cm}$ of the core average 14.1, with comparable average ratios in the upper $5 \mathrm{~cm}$ of the monolith (13.2). These data, in line with expectations, suggest that the time period represented in the upper $30 \mathrm{~cm}$ of the core are found in the monolith record. As a result, it is difficult to reconcile the diatom slotting data for these upper sediments. It may be that because this period is characterised by lower water levels in Kangaroo Creek Reservoir than any similar length period (Fig. 7), processes such as density currents operated at a scale which influenced the composition of the core diatom assemblages, but were not readily detectable as massive deposits. Shotbolt et al. (2005) indicate that such a situation provides a substantial challenge for the study of reservoir sediments since records of environmental change are modified in ways that are not easily identified.

In summary, it appears that a number of broadly consistent correlations can be derived between a core extracted from the bottom of Kangaroo Creek Reservoir and a record of sediments deposited on a disused bridge perched $15 \mathrm{~m}$ above the reservoir bed. However, the higher energy setting of the core means that much of the proxy record preserved is likely to be unrepresentative of the average conditions in the reservoir water column. Moreover, with particular reference to the diatom record, it is clear that, at a minimum, half the core record deposited at the bottom of the reservoir is representative of diatom composition of an unknown upstream location. Furthermore, despite the construction of monolith and core diatom data sets designed to minimise any discrepancy between the depositional setting of the two records by focussing on a limited number of planktonic taxa and excluding a priori some core sections, it was not possible to utilise sequence slotting to reliably refine the chronology of the core, with the output from the sequence slotting contrasting to other lines of evidence. This, in combination with the unlikely notion that the top $27.5 \mathrm{~cm}$ of the core is not preserved in the monolith, indicates that the diatom data are not useful for refining the chronology of the core record. Furthermore, our inability to derive reliable correlations between the bridge monolith and core diatom sequences suggests that, even in the absence of large density currents, reservoir bottom diatom sedimentation is affected by processes that do not reflect water column conditions.

An age-depth record for the core

Age-depth curves for the core record (Fig. 9) include the record based on proposed density currents (solid 
line), sequence slotting (dotted line) and a calibrated ${ }^{210} \mathrm{~Pb}_{\mathrm{ex}}$ CRS chronology. The CRS chronology is determined assuming the base of the core corresponds to 1981 (approximate uncertainty \pm 1 year). Equations (4) and (5) are used to calculate dates with the known time horizons being the years 2001 (depth $0 \mathrm{~cm}$ ) and 1981 (depth $130 \mathrm{~cm}$ ). In general the ${ }^{210} \mathrm{~Pb}_{\mathrm{ex}}$ CRS chronology supports our proposed density current record over the sequence slotting approach, with the only significant deviation between the density current record and the CRS chronology (1-2 years) occurring during the period of low sedimentation in the mid-late 1990s. It is likely that the assumption of constant ${ }^{210} \mathrm{~Pb}_{\mathrm{ex}}$ flux during this period of low sedimentation is not valid, and is responsible for the dating differences.

Whilst the proposed density current record obviously emphasises the rapid accumulation that occurs in bottom sediments during the deposition of density currents, it also allows for some comparisons to be made of the mean sedimentation rates that occur between density currents. Whilst substantial caveats must be placed on such inferences, since allochthonous density currents can entrain autochthonous sediment, Fig. 9 indicates that, following the last density inflows, from mid-1996 to mid-2001, sedimentation was notably slower than the periods 1981-1992 and 19921996, which followed the first and second inflows, respectively. The apparent slowing of sedimentation since mid 1996 is also observed in the CRS-derived sedimentation rate from the bridge monolith record (Fig. 3b). The proposed ${ }^{210} \mathrm{~Pb}_{\mathrm{ex}}$ bottom core chronology also indicates a reduction in sedimentation by almost half since $\sim 1995$. Since 1996, stream flows to Kangaroo Creek Reservoir have been markedly reduced relative to the other periods (Fig. 6), a fact consistent with our sedimentation observations.

\section{Conclusions}

Palaeolimnological analyses of sediments deposited in Kangaroo Creek Reservoir have revealed the history of sediment deposition in two contrasting sedimentary environments. The record preserved on a submerged disused bridge covers the full period from first filling to 2001, with the exception of some short time periods when the bridge was exposed during reservoir draw down. By contrast, the 128.5-cm core record appears to only span the period since late 1981.

The CRS-based chronology for monolith sediments indicates that, on a decadal timescale, sediment accumulation on the George Road Bridge has not undergone major fluctuations. The high-resolution diatom analysis of bottom reservoir sediments, however, has provided indications of very different basal sediment behaviours. In particular, diatoms show that the core record is characterised by substantial sections with high proportions of non-planktonic diatoms and sediment properties that are distinct from the remainder of the record. These sections were deposited rapidly by density currents that occurred at times of high upstream discharge. These findings have important implications for catchment management. In particular, although these sections contain $47 \%$ of the sediments deposited at the core site, they are likely to have been deposited in less than $5 \%$ of the time. Despite this, it appears unlikely that that this deposition resulted in large increases in the pool of sediment-bound nutrients since these sediments had relatively low concentrations of phosphorus and were rapidly buried. The bottom sediment accumulation rate during periods between density currents exhibits a trend similar to that observed in the perched bridge monolith record, with an apparent slowing of sediment accumulation from 1996 to 2001, possibly as a result of reduced catchment inflows.

Despite the very different depositional histories of the two records presented, correlation based on a variety of indicators was still possible. Notably, diatoms provided a less reliable indicator with which to correlate the records than the radionuclide data. It is clear that, in reservoirs such as this, cores raised from bottom sediments may be characterised by sequences in which much of the sediment is not representative of the long-term history of the reservoir water column. Hence, although reservoirs still represent a relatively untapped resource for palaeolimnological study, considerable caution is warranted when interpreting reservoir diatom records. In this study, bottom sediment accumulation associated with phases of sediment mobility, presumably driven by density currents, were readily identifiable. However, the problem of a background deposition of allochthonous diatoms was also highlighted, particularly by the inability to slot sequences in the upper part of the core record. This issue perhaps provides a 
fundamental challenge to interpreting diatom-based records from reservoirs.

Acknowledgments This project was supported by the Torrens Catchment Water Management Board and the Australian Research Council via Linkage project LP0347579 to PG and Peter Wallbrink. Diatoms were counted by Greg Smith, Cameron Barr, Jonathan Tyler, Nicole Morcom and J.T. Teresa Heneker, Department of Land, Water and Biodiversity Conservation provided much of the hydrological data. Peter Murphy, SA Water, provided the water level to volume conversion tools for Kangaroo Creek Reservoir.

\section{References}

Anon (2000) Torrens Catchment Management Plan. Torrens Catchment Modelling. Tonkin Consulting, Adelaide

Appleby PG (2001) Chronostratigraphic techniques in recent sediments. In: Last WM, Smol JP (eds) Tracking environmental change using lake sediments, vol 1: basin analysis, coring and chronological techniques. Kluwer Academic Publishers, Dordrecht, pp 171-204

Appleby PG, Oldfield F (1978) The calculation of lead-210 dates assuming a constant rate of supply of unsupported ${ }^{210} \mathrm{~Pb}$ to the sediment. Catena $5: 1-8$. doi:10.1016/S03418162(78)80002-2

Appleby PG, Oldfield F (1992) Application of lead-210 to sedimentation studies. In: Ivanovich M, Harmon RS (eds) Uranium-series disequilibrium: applications to earth, marine and environmental sciences. Clarendon Press, Oxford, pp 731-778

Battarbee RW, Jones VJ, Flower RJ, Cameron NG, Bennion H, Carvalho L, Juggins S (2001) Diatoms. In: Smol JP, Last WM, Birks HJB (eds) Tracking environmental change using lake sediments, vol 3: terrestrial, algal and siliceous indicators. Kluwer Academic Publishers, Dordrecht, pp 155-202

Callender E (2000) Geochemical effects of rapid sedimentation in aquatic systems: minimal diagenesis and the preservation of historical metal signatures. J Paleolimnol 23: 243-260. doi:10.1023/A:1008114630756

Chambers JW, Cameron NG (2001) A rod-less piston corer for lake sediments: an improved, rope-operated percussion corer. J Paleolimnol 25:117-122. doi:10.1023/A:1008181 406301

Clark RM (1985) A FORTRAN program for constrained sequence-slotting based on minimum combined path length. Comput Geosci 11:605-617. doi:10.1016/0098-30 04(85)90089-5

Clark JS, Hussey TC (1996) Estimating the mass flux of charcoal from sediment records: the effect of particle size, morphology, and orientation. Holocene 6:129-144. doi: 10.1177/095968369600600201

Clark RL, Wasson RJ (1986) Reservoir sediments. In: DeDeckker P, Williams WD (eds) Limnology in Australia. CSIRO, Melbourne, pp 497-507

Davis J, Koop K (2006) Eutrophication in Australian rivers, reservoirs and estuaries-a southern hemisphere perspective on the science and its implications. Hydrobiologia 559:23-76. doi:10.1007/s10750-005-4429-2

Dean WE (1974) Determination of carbonate and organic matter in calcareous sediment and sedimentary rocks by loss on ignition: comparison with other methods. J Sediment Petrol 44:242-248

Delcoigne A, Hansen P (1975) Sequence comparison by dynamic programming. Biometrika 62:661-664. doi: 10.1093/biomet/62.3.661

Garzanti E, Ando S, Vezzoli G, Ali Abdel Megid A, El Kammar A (2006) Petrology of Nile River sands (Ethiopia and Sudan): sediment budgets and erosion patterns. Earth Planet Sci Lett 252:327-341. doi:10.1016/j.eps1.2006.10.001

Grimm EC (1987) CONISS: a FORTRAN 77 program for stratigraphically constrained cluster analysis by the method of incremental sum of squares. Comput Geosci 13:13-35. doi:10.1016/0098-3004(87)90022-7

Hall RI, Leavitt PR, Dixit AS, Quinlan R, Smol JP (1999) Limnological succession in reservoirs: a paleolimnological comparison of two methods of reservoir formation. Can J Fish Aquat Sci 56:1109-1121. doi:10.1139/cjfas56-6-1109

Heneker TM (2003) Surface water assessment of the upper River Torrens catchment. Department of Water, Land and Biodiversity Conservation, Adelaide

Kim JG (2005) Assessment of recent industrialization in wetlands near Ulsan, Korea. J Paleolimnol 33:433-444. doi: 10.1007/s10933-004-7617-6

Krammer K, Lange-Bertalot H (1986) Bacillariophyceae. 1: Teil: Naviculaceae. Gustav Fischer Verlag, Jena

Krammer K, Lange-Bertalot H (1988) Bacillariophyceae. 2: Teil: Bacillariaceae, Epthimiaceae, Surirellaceae. Gustav Fischer Verlag, Jena

Krammer K, Lange-Bertalot H (1991a) Bacillariophyceae. 3: Centrales, Fragilariaceae, Eunotiaceae. Gustav Fischer Verlag, Stuttgart

Krammer K, Lange-Bertalot H (1991b) Bacillariophyceae. 4: Achnanthes, Kritische Ergänzunhen zu Navicula (Lineolatae) und Gomphonema Gesamtliteraturverzeichnis Teil 1-4. Gustav Fischer Verlag, Stuttgart

Murray AS, Marten R, Johnston A, Martin P (1987) Analysis of naturally occurring radionuclides at environmental concentrations by gamma spectrometry. J Radioanal Nucl Chem 115:263-288. doi:10.1007/BF02037443

Outhet DN (1991) Sedimentation in variable reservoirs in New South Wales. Unpublished Ph.D. thesis, School of Earth Science, Macquarie University, Sydney

Rhodes AN (1995) A method for the preparation and quantification of microscopic charcoal from terrestrial and lacustrine sediment cores. Holocene 8:113-117. doi:10.1191/ 095968398671104653

Robbins JA (1978) Geochemical and geophysical applications of radioactive lead. In: Nriagu JO (ed) The biogeochemistry of lead in the environment, Part A. Elsevier Scientific, Amsterdam, pp 285-393

Shotbolt LA, Thomas AD, Hutchinson SM (2005) The use of reservoir sediments as environmental archives of catchment inputs and atmospheric pollution. Prog Phys Geogr 29:337-361. doi:10.1191/0309133305pp452ra

Shotbolt L, Hutchinson S, Thomas A (2006) Sediment stratigraphy and heavy metal fluxes to reservoirs in the 
Southern Pennine Uplands, UK. J Paleolimnol 35:305322. doi:10.1007/s10933-005-1594-2

Sonneman JA, Sincock A, Fluin J, Reid M, Newall P, Tibby J, Gell P (2000) An Illustrated guide to common stream diatoms from temperate Australia. Cooperative Research Centre for Freshwater Ecology, Thurgoona

SPSS (2004) SPSS for windows 13.0. SPSS, Chicago

Thompson R, Clark RM (1989) Sequence slotting for stratigraphic correlation between cores: theory and practice. J Paleolimnol 2:173-184. doi:10.1007/BF00202045

Tibby J (2001) Diatoms as indicators of sedimentary processes in Burrinjuck reservoir, New South Wales, Australia. Q Int 83-85:245-256. doi:10.1016/S1040-6182(01)00043-X

Tibby J (2004) Development of a diatom-based model for inferring total phosphorus in south-eastern Australian water storages. J Paleolimnol 31:23-36. doi:10.1023/ B:JOPL.0000013272.25122.2a

Turekian KK, Nozaki Y, Benninger LK (1977) Geochemistry of atmospheric radon and radon products. Annu Rev Earth Planet Sci 5:227-255. doi:10.1146/annurev.ea.05.050177. 001303

Wasson RJ, Clark RL, Nanninga PM, Waters J (1987) ${ }^{210} \mathrm{~Pb}$ as a chronometer and sediment tracer, Burrinjuck Reservoir, Australia. Earth Surf Process Landf 12:399-414. doi: 10.1002/esp.3290120406

Yoshikawa S, Yamaguchi S, Hata A (2000) Paleolimnological investigation of recent acidity changes in Sawanoike Pond, Kyoto, Japan. J Paleolimnol 23:285-304. doi: 10.1023/A:1008199830698 